\title{
A century of nuptiality decline in South Africa: A longitudinal analysis of census data
}

\author{
Michel Garenne \\ ${ }^{1}$ Institut de Recherche pour le Développement (IRD), UMI Résiliences, Bondy, France \\ ${ }^{2} \mathrm{MRC} /$ Wits Rural Public Health and Health Transitions Research Unit, School of Public Health, \\ Faculty of Health Sciences, University of the Witwatersrand, Johannesburg \\ ${ }^{3}$ Institut Pasteur, Epidémiologie des Maladies Emergentes, Paris, France \\ Michel.Garenne@pasteur.fr
}

\section{Abstract}

The study uses data from eight censuses conducted between 1970 and 2011 to reconstruct long term trends in terminal celibacy in South Africa. The cohort analysis covers those born between 1870 and 1971. Results show a quasi-stable prevalence of terminal celibacy for cohorts born before 1920, followed by a steep rise. Levels and trends were notably different for the four population groups. Black/Africans had the highest level at endpoint ( $50 \%$ celibate), despite lower levels at onset, followed by Coloured (34\%). Indian/Asian had the lowest level at endpoint (14\%). White/European had highest levels at onset, and intermediate values at endpoint (17\%). Differences were large by ethnicity, Zulu and Swazi having the highest prevalence of terminal celibacy (60\%). Correlations with development were complex, with higher values among persons with lower education, and those living in urban areas, and lower values among those who were employed. Overall, cultural factors dominated the rise in terminal celibacy in South Africa.

Key words: Terminal celibacy; Marriage; Cultural factors; Race; Ethnicity; Socio-economic factors; Education; Urbanization; Employment; Economic development; South Africa.

\section{Introduction}

Long term demographic trends have called the attention of demographers, however the focus has been rather on fertility, mortality and migration, and rarely on nuptiality. [Coale, 1969; Coale \& Watkins 1986; Stolnitz 1955, \&1956] Furthermore, most historical studies on nuptiality trends focus on age at first marriage, more susceptible to changes for a variety of reasons, rather than on proportions ever-marrying, assumed to be more stable. There are long-term studies on nuptiality in the USA, where marriage has been undergoing major changes in the $20^{\text {th }}$ century in particular for the African/American population. [Eekelaar \& Katz 1985; Elliot et al. 2012; Rodgers \& Thornton 1985; Thornton \& Freedman 1982; Tucker \& Mitchell-Kernan 1995a,b] For sub-Saharan Africa, only few syntheses are available, despite numerous local studies. For a long time marriage was seen as universal and stable in sub-Saharan Africa. [Lestaeghe et al. 1989; van de Walle 1967, 1993; Westoff et al. 1994] This is no longer the case, and in particular age at marriage has been increasing rapidly, and proportions ever-married have been declining, especially in urban areas [Garenne 2004, 2014; Garenne \& Zwang 2006;
Odimegwu \& Kekovole 2014; Rutaremwa 2014; Westoff 2003].

Change in marriage patterns, and in particular in proportions never-married, may be associated with cultural factors and social change, or with socio-economic factors and economic development, or sometimes with the marriage market, or a combination of those in complex dynamics. This is found all over the world, including in Africa. [Dixon 1971; Garenne 2004; Mare \& Winship 1991]

South Africa presents outstanding patterns of nuptiality, with large segments of adult populations who never marry. This pattern is also found in neighbouring countries sharing a common economic and social history, such as Namibia and Botswana, but not in other parts of sub-Saharan Africa. For instance, in DHS surveys, the only African countries where the proportion of women never-married at age 45-49 exceeded $8 \%$ were Botswana, Namibia, South Africa and Swaziland, whereas the average for other countries was $1.1 \%$. [DHS web site, Stat Compiler, accessed July 13, 2015.] The current South African situation of low proportions of ever-married persons and atypical household 
structures has generated numerous studies. [Budlender et al. 2004; Leonard et al. 2015; Palamuleni 2010; Zielh 2001] Some of this work showed a decline in proportion ever-married from census to census. [Palamuleni 2010] However, there is no published synthesis on long term trends in proportions never-married in South Africa. Furthermore, the country has a complex history, with numerous migrant groups mixing or not mixing with indigenous populations over the past four centuries, which makes a complex social fabric with several races, numerous ethnic groups, and several levels of development, all likely to have different nuptiality dynamics.

The aim of this study was to reconstruct trends in proportions never-married as far back in time as possible, using census data made available to researchers on computer media by the South African Statistical Office (Stats-SA) and the IPUMS- International program. The recent availability of census data, thanks to digitalization and the open-access policy, gives new opportunities for studying long term changes in marital status in developing countries. This work follows earlier work on nuptiality and household structures using census data in South Africa. [Budlender et al. 2004; Leonard et al. 2015; Palamuleni 2010; Zielh 2001]

\section{Data and Methods}

South African censuses

The micro-data of eight censuses conducted in South Africa are computerized and available for research: three are already part of the IPUMSInternational project (1996, 2001, 2007), and the other five are available on the Stats-SA web site (1970, 1980, 1985, 2011). The first four censuses did not cover the whole of South Africa in terms of geographical and racial divisions. In the earlier years, the country was divided into three major geographical areas (the Republic of South Africa or RSA, the self-governed territories or 'Homelands', and the so-called independent TBVC states: Transkei, Bophuthatswana, Venda, Ciskei). The population was divided into four racial groups (Black/African. Coloured, Indian/Asian, White/European). The 1970 census files covered the last three population groups, and a 5\% sample of the Black/African group, but did not cover the TBVC states. The 1980 census files covered the RSA, and only Bophuthatswana among the TBVC states, although this last census did not include marital status, and therefore was not included in this analysis. The 1985 census covered the RSA only. The 1991 census covered the RSA and three of the TBVC states (Ciskei was not available in the computer files). For the first 4 censuses, the complete datasets were available. For the last 4 censuses, only samples were available. Lastly, the 2007 Community Survey was itself based on a sample in the field, and not a complete census. (Table 1)

Table 1: Characteristics of the eight South African censuses

\begin{tabular}{|c|c|c|c|c|c|c|c|c|}
\hline & \multicolumn{8}{|c|}{ Census } \\
\hline & 1970 & 1980 & 1985 & 1991 & 1996 & 2001 & 2007 & 2011 \\
\hline \multicolumn{9}{|l|}{ Size } \\
\hline Population & 21.794 & 30.173 & 32.673 & 37.738 & 40.584 & 44.820 & 48.502 & 51.771 \\
\hline Coverage & Partial & Partial & Partial & Partial & Total & Total & Sample & Total \\
\hline Sample & 7.226 & 26.529 & 23.386 & 22.560 & 3.621 & 3.726 & 1.048 & 4.419 \\
\hline \multicolumn{9}{|c|}{ Number of categories } \\
\hline Marital status & 5 & 5 & 5 & 5 & 6 & 8 & 8 & 6 \\
\hline Race & 4 & 4 & 4 & 4 & 4 & 4 & 4 & 4 \\
\hline $\begin{array}{l}\text { Ethnicity } \\
\text { Celibacy stud }\end{array}$ & 20 & 18 & 18 & 25 & 26 & 11 & NA & 13 \\
\hline Women $40+$ & 0.913 & 2.675 & 2.742 & 2.887 & 0.440 & 0.514 & 0.141 & 0.662 \\
\hline Men 40+ & 0.849 & 2.584 & 2.495 & 2.469 & 0.354 & 0.394 & 0.108 & 0.513 \\
\hline$\%$ celibate F & $8.2 \%$ & $12.5 \%$ & $12.7 \%$ & $13.9 \%$ & $17.5 \%$ & $21.1 \%$ & $24.9 \%$ & $29.2 \%$ \\
\hline$\%$ celibate M & $8.8 \%$ & $15.0 \%$ & $14.2 \%$ & $15.7 \%$ & $18.4 \%$ & $21.8 \%$ & $24.6 \%$ & $28.7 \%$ \\
\hline
\end{tabular}

Note: Population in million. The celibacy study was based on adults of both genders age $40+\mathrm{NA}=$ not available. 
Marital status and terminal celibacy

With the sole exception of Bophuthatswana 1980 (excluded from this study), all censuses included current marital status in at least 5 categories: never-married, living with someone (common-law union), married, widowed, divorced/separated. For the purpose of this study, terminal celibacy was defined by the first two categories (never-married, or living with someone) for persons aged 40 years and above. It is therefore opposed to the last three categories (married, widowed, divorced) for which there is evidence of an earlier marriage in the census file. The same definition was used by other authors working in South Africa. [Hosegood et al. 2009; Udjo 2001] This definition bears some potential problems, since it is based on current status and not on a formal definition of being ever-married by age 40. For instance, the first group (called here 'celibates') might include persons who were in fact married earlier, who lost their spouse and are now living with someone. Conversely, the second group (evermarried) might include persons who married at an older age ( $>40$ years), while remaining single for a long period of time. Furthermore, as true in any census, the declaration of marital status could be misleading, in particular for older persons (age > 80 years). However, as will be seen later, the consistency between censuses was impressive, so that data errors seem to be a minor issue for this study.

\section{Age and date of birth}

All censuses included either age, in integer number of years from birth to age 100 or above (often up to 119 years) or year of birth. Birth cohorts used for this study were therefore defined as either the year of birth if stated, or as the difference between the census year and the age. The study covers therefore potentially all cohorts (year of birth) from 1870 to 1971, which, assuming a mean age at marriage of 30 years, corresponds roughly to the marriage experience during the whole twentieth century. The earlier cohorts, those born before 1890, were represented by survivors whose age exceeded 80 years at the first census, and might therefore bear serious biases due to small numbers, selection and misreporting, and should be considered with caution.

\section{Population group and ethnicity}

South Africa's social fabric is complex, with several indigenous ethnic groups and a large number of migrants from all over the world, and in particular from Europe and Asia. All eight censuses distinguished the same four population groups. In addition, all but the 2007 Community Survey provided some information on ethnicity, usually based on the main language spoken at home, sometimes based on the ethnic group as declared in the census. The list of languages or ethnic groups varied among the censuses, and had to be standardized for the purpose of this study. Among the Black/African groups, the nine main South African groups were considered: Zulu, Xhosa, Ndebele (North and South), Swazi, Tswana, Pedi (Northern Sotho), Sotho (Southern), Shangaan (Tsonga), and Venda, to which two other groups were added: Black/African speaking Afrikaans or English (who are usually a more urbanized elite), and those speaking other languages, who are mostly immigrant Africans from neighbouring countries. Among the Coloureds, two groups were considered: those speaking Afrikaans or English, and those speaking another language. Among the Indian/Asians, two groups were considered: those speaking Afrikaans or English, and those speaking an Asian language (Hindi, Urdu, Gujrati, Tamil, Chinese, etc.). Among the White/European, three groups were considered: speakers of Afrikaans, speakers of English, and speakers of another language (usually European languages such as Dutch, German, French, Italian, Greek etc.).

\section{Statistical methods}

Basic cross-tabulations allowed computing the prevalence of terminal celibacy by cohort (year of birth), and to study trends. For the final analysis, the eight censuses were merged together simply by adding celibates and noncelibates by year of birth. Trends in the proportion of celibates were fitted either by linear-logistic regression, or by splines using second-degree polynomial on yearly cohort data. Basic multivariate analysis using linear logistic regression (celibate vs non-celibate) was conducted for investigating the effect of socioeconomic factors.

\section{Results}

Trends in terminal celibacy (whole country)

Comparing the eight censuses by year of birth revealed dramatic changes in terminal celibacy over the years. Whereas for women born in 1880-1899 some $8.7 \%$ ended celibate (data from the 1980 census), some $43.8 \%$ of women born in 1970-1971 were celibate in 2011, about 5 -times more. Corresponding values for men were similar: proportion celibate was $11.6 \%$ for 
men born in 1880-1899 and 45.9\% for those born in 1970-1971. The increase in terminal celibacy was gradual, with little change until the 1920 cohort, followed by a fast rise thereafter, which continued unabated until the last cohort available. This corresponds roughly to stable marriages in the first half of the $20^{\text {th }}$ century, and dramatic changes after 1950, which continued until 2011, the last point available. Overall, the eight censuses were consistent, and all showed a similar rise in terminal celibacy at about the same time. The most notable inconsistency was that of the earlier cohorts at the 1970 census, and was entirely due to erratic data from the $5 \%$ sample of the Black/African population, which appeared seriously biased, and was ignored in the final analysis. Other inconsistencies were minor, and due to erratic data at very old ages, in particular for those aged 80 years and above in the 1996, 2001 and 2011 censuses. Proportions celibate were also higher in the 1980 census for the 1940-1941 cohorts for both sexes. The fact that a longer recall period could lead either to systematic bias (due to later changes in marital status) or to recall bias (due to mis-declaration) was tested by comparing the prevalence of terminal celibacy for the same cohorts and the various censuses in a multivariate analysis. Results showed no effect of census year $(P=0.252)$, that is no effect of the recall period, which indicated that censuses could be merged in a single file for the final cohort analysis. (Figure 1)

Figure 1: Trends in terminal celibacy, by census, South Africa

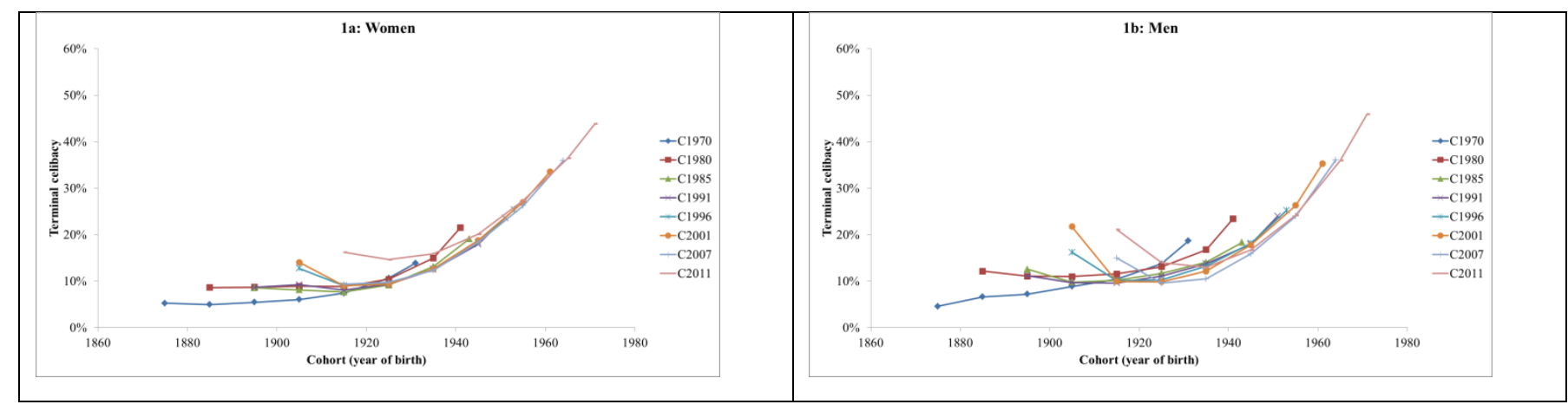

Trends in terminal celibacy by population group Trends in terminal celibacy were different for the four population groups. The group the most affected by the increase in terminal celibacy was the Black/African group. For this group, for both men and women, terminal celibacy was fluctuating little before 1920, with minor ups and downs, and a rather declining trend from cohorts born between 1890 and 1920. For these cohorts, the proportions of celibates were higher for men than for women. Then, terminal celibacy started to rise, first slowly, then rapidly, to reach very high values exceeding half of the cohort $(51.3 \%$ for women and $52.8 \% \%$ for men for those born in 1970-1971). The gap between men and women disappeared after 1930, and prevalence of terminal celibacy was even somewhat higher for women than for men for cohorts born between 1940 and 1960. (Figure 2a)

Figure 2: Trends in terminal celibacy, by population group and gender, South Africa

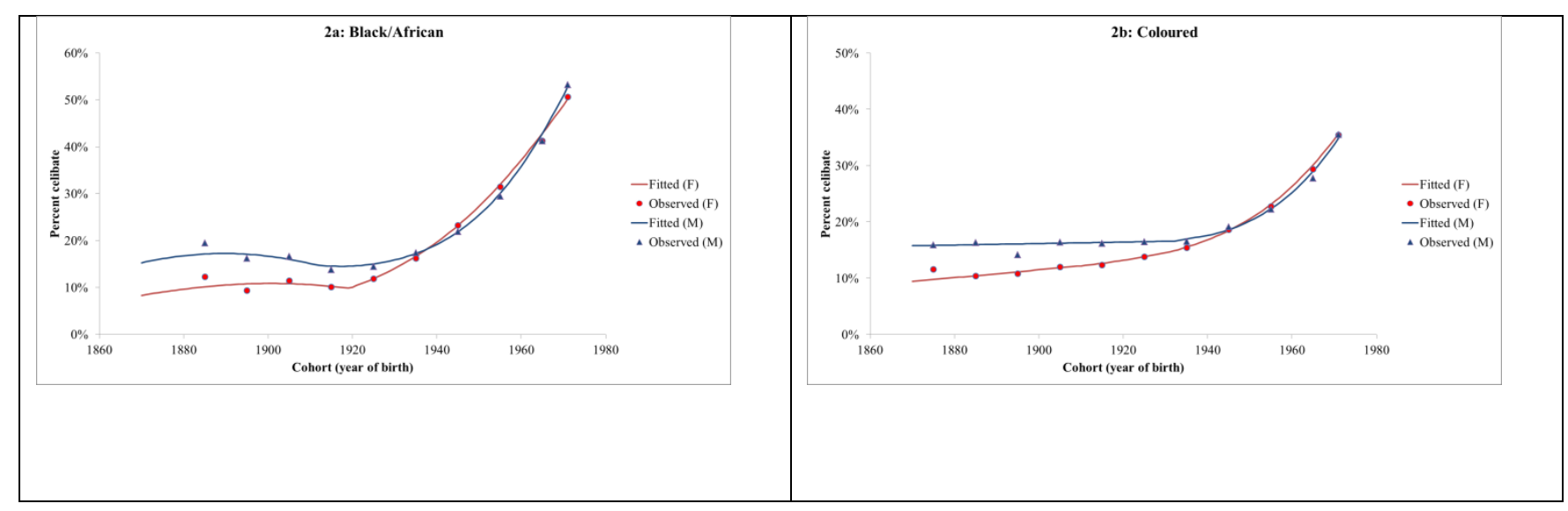




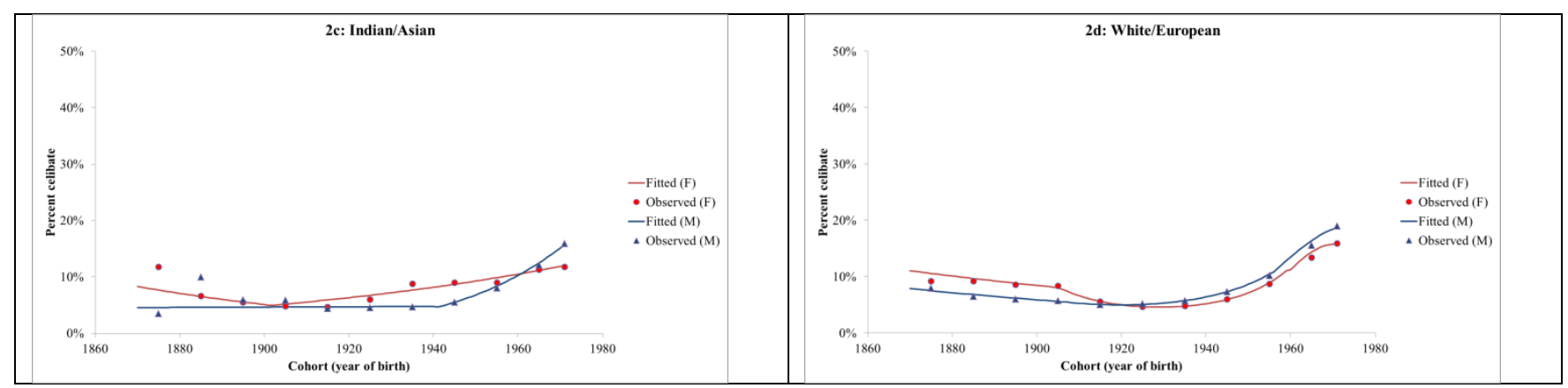

Corresponding trends for the Coloured population were similar, with first a rather stable situation, with higher proportions for men, followed by a steep rise. Baseline values of the proportion of celibates were similar to those of the first group. The onset of the rise occurred some 10 years later, and the magnitude of the change was smaller than for the Black/African group, with peak values of $35.7 \%$ for women and $34.9 \%$ for men. (Figure $2 b$ )

The last two groups had different profiles. The Indian/Asian group had lower prevalence of terminal celibacy for those born before 1900 (6.1\% for women and $4.6 \%$ for men), and the rise was smaller after 1920 . Note that terminal celibacy tended to be higher for women in this group, except in the more recent cohorts born after 1960. (Figure 2c)

The White/European group had declining prevalence of terminal celibacy for cohorts born between 1880 and 1930, then a steep rise for men and women alike, with some levelling off for the most recent cohorts reaching $15.9 \%$ for women and $18.9 \%$ for men born in 1970-71. In this group, prevalence of terminal celibacy was higher for women than for men before 1930, and somewhat lower thereafter. Prevalence of terminal celibacy averaged $9.3 \%$ for women born between 1880 and 1899 , and $6.5 \%$ for men of the same cohorts, a typical feature of European populations of that time period. (Figure 2d)
Trends in terminal celibacy by ethnicity

Among the Black/African groups speaking South African languages, all had moderate levels of terminal celibacy at onset (cohorts 1870-1910), ranging from $10 \%$ to $18 \%$ for both sexes combined, and high levels at endpoint (cohorts 1970-1971), ranging from $40 \%$ to $61 \%$. Record high values at endpoint were for Swazi (60.7\%) and Zulu (60.0\%). Note that the Swazi had also the highest values at onset (17.8\%), but not the Zulu group, who was on the low side at onset $(12.0 \%)$. Lowest values at endpoint were for the Venda group (40.5\%), whereas the other groups were more homogenous, ranging from $47 \%$ to $57 \%$. Correlation between values at onset and value at endpoint was moderate $(\rho=0.44)$, revealing a variety of dynamics over time. Largest increases from onset to endpoint were for Zulu (+48\%), Swazi $(+42.3 \%)$, Ndebele $(+41.3 \%)$, and Tswana $(+40.8 \%)$. Smallest increases from onset to endpoint were for Venda $(+27.1 \%)$, although still important. The remainder group, speaking Afrikaans, English or other African languages (mostly migrants from other African countries) behaved differently, with much higher values at baseline, and much lower values at endpoint, and only a small increase over the years in comparison with South African groups. (Table 2)

Table 2: Prevalence of terminal celibacy (average of men and women), by ethnicity and cohort, Black/African groups, South Africa

\begin{tabular}{|c|c|c|c|c|c|}
\hline \multirow{2}{*}{$\begin{array}{l}\text { Ethnicity/ } \\
\text { Lanquage }\end{array}$} & \multicolumn{5}{|c|}{ Cohort (year of birth) } \\
\hline & $<1910$ & 1910-1929 & $1930-49$ & $1950-69$ & $1970-71$ \\
\hline Zulu & $12.0 \%$ & $13.1 \%$ & $23.1 \%$ & $41.5 \%$ & $60.0 \%$ \\
\hline Swazi & $17.8 \%$ & $18.9 \%$ & $26.8 \%$ & $41.9 \%$ & $60.7 \%$ \\
\hline Ndebele & $12.6 \%$ & $10.5 \%$ & $16.6 \%$ & $31.8 \%$ & $53.9 \%$ \\
\hline Xhosa & $15.0 \%$ & $13.3 \%$ & $20.4 \%$ & $33.7 \%$ & $48.9 \%$ \\
\hline Tswana & $15.8 \%$ & $16.3 \%$ & $25.4 \%$ & $38.8 \%$ & $56.7 \%$ \\
\hline Sotho & $11.0 \%$ & $10.6 \%$ & $16.8 \%$ & $29.9 \%$ & $47.0 \%$ \\
\hline Pedi & $9.9 \%$ & $9.7 \%$ & $15.7 \%$ & $28.4 \%$ & $48.1 \%$ \\
\hline Shangaan/Tsonga & $13.5 \%$ & $11.6 \%$ & $15.0 \%$ & $29.0 \%$ & $50.7 \%$ \\
\hline
\end{tabular}




\begin{tabular}{llllll} 
Venda & $13.5 \%$ & $10.8 \%$ & $12.9 \%$ & $22.4 \%$ & $40.5 \%$ \\
Afrikaans/English & $30.5 \%$ & $22.8 \%$ & $23.3 \%$ & $30.2 \%$ & $39.0 \%$ \\
Other language & $34.9 \%$ & $23.4 \%$ & $24.0 \%$ & $32.7 \%$ & $39.9 \%$ \\
\hline
\end{tabular}

In the Coloured group, there were some differences between speakers of Afrikaans or English, who had higher prevalence of terminal celibacy at onset and lower values at endpoint than others (both sexes combined). A similar feature was found among the Indian/Asian, although at lower levels than in the Coloured group. In the White/European group, the Afrikaans speakers had lower values at baseline and at endpoint than the other two categories, but still a marked increase in terminal celibacy (+10\%).
The English speakers had higher values at onset, and also a moderate increase $(+11 \%)$. The remainder group speaking other languages (mostly European languages) had the largest increase among the White/European group $(+18 \%)$. Even though the last three population groups were less fragmented than the Black/African group, differences between subgroups were still notable, revealing different marriage dynamics. (Table 3)

Table 3: Prevalence of terminal celibacy (average of men and women), by ethnicity and cohort, groups other than Black/African, South Africa

\begin{tabular}{lccccc}
\hline Race/ & \multicolumn{5}{c}{ Cohort (year of birth) } \\
\cline { 2 - 5 } Language & $<1910$ & $1910-1929$ & $1930-49$ & $1950-69$ & $1970-71$ \\
\hline $\begin{array}{l}\text { Coloured } \\
\text { Afrikaans/English }\end{array}$ & $13.9 \%$ & $15.2 \%$ & $17.5 \%$ & $24.8 \%$ & $34.8 \%$ \\
$\begin{array}{l}\text { Other language } \\
\text { Indian/Asian }\end{array}$ & $11.2 \%$ & $14.1 \%$ & $25.9 \%$ & $36.9 \%$ & $46.0 \%$ \\
$\begin{array}{l}\text { Afrikaans/English } \\
\text { Other language }\end{array}$ & $8.1 \%$ & $5.4 \%$ & $6.6 \%$ & $8.8 \%$ & $12.8 \%$ \\
$\begin{array}{l}\text { White/European } \\
\text { Afrikaans }\end{array}$ & $3.4 \%$ & $4.5 \%$ & $10.3 \%$ & $15.5 \%$ & $21.0 \%$ \\
English & $5.3 \%$ & $4.0 \%$ & $4.8 \%$ & $9.0 \%$ & $15.2 \%$ \\
Other language & $8.8 \%$ & $6.1 \%$ & $7.1 \%$ & $12.7 \%$ & $19.6 \%$ \\
& $7.1 \%$ & $5.4 \%$ & $6.6 \%$ & $16.8 \%$ & $25.2 \%$ \\
\hline
\end{tabular}

Statistical analysis of the risk of terminal celibacy Since all groups underwent a rise in terminal celibacy after 1920, but at different levels, the various levels were estimated by linear-logistic regression, after controlling for time trend $(+4 \%$ per year) and sex (RR=1.02 for males). Overall, results confirmed the univariate analysis, in particular that population group (race) had a dominating effect, and that ethnicity had additional effects. For population groups, White and Indian/Asian appeared at similar risk, while Coloured had a 3.1 times higher risk and Black/African a 4.2 times higher risk. Among the Black/African groups, Zulu, Swazi and Tswana appeared at higher risk, while Pedi, Shangaan and Venda were at lower risk than the average for this group. Among the Coloured and among the Indian/Asian, those speaking Afrikaans or English were at lower risk than others. Among the White/Europeans, those speaking Afrikaans were at lower risk $(R R=0.74)$, while those speaking English were at higher risk $(R R=1.11)$ than others (Table 4). For White, speakers of Afrikaans and English were compared with others. All differences were highly statistically significant. 
Table 4: Net effect of race and ethnicity on the risk of terminal celibacy, after controlling for time trend and sex, South Africa, cohorts 1920-1971

\begin{tabular}{llll}
\hline Category/Language & $\mathrm{RR}$ & Category/Language & $\mathrm{RR}$ \\
\hline Population group & & Black/African & \\
Black/African & 4.16 & Zulu & 1.40 \\
Coloured & 3.06 & Swazi & 1.62 \\
Indian/Asian & 0.97 & Ndebele & 0.95 \\
White (ref) & 1.00 & Xhosa & 1.11 \\
Other groups & & Tswana & 1.41 \\
Coloured/European & 0.81 & Sotho & 0.90 \\
Asian/European & 0.71 & Pedi & 0.84 \\
White/Afrikaans & 0.74 & Shangaan & 0.85 \\
White/English & 1.11 & Venda & 0.64 \\
& & Other (ref) & 1.00 \\
\hline
\end{tabular}

NB: $\mathrm{RR}=$ relative risk. For Coloured and Indian/Asian, speakers of European languages (Afrikaans or English) were compared with others.

Relationship with economic development in recent years

The relationship of terminal celibacy with socioeconomic correlates was investigated among men and women aged 40-49 at the 2011 census (the most recent cohorts). In a first run the net effect of population group, education, and urban residence was investigated, after controlling for cohort (net effect of $+7.5 \%$ a year) and sex ( $R R=1.05$ for males). Results showed a strong independent effect of race, and a mild effect of urban residence. As seen in the univariate analysis, when compared with
White/European, Black/Africans had the highest risk of terminal celibacy $(R R=3.21)$ followed by Coloured $(R R=1.72)$, whereas Indian/Asian had a lower risk $(R R=0.67)$. Compared with persons with higher education who had the lowest risks, there was a marked gradient of risks with level of education: $R R=1.33$ with other levels, 1.47 with complete secondary, 1.96 with incomplete secondary, 2.25 with complete primary, 2.57 with incomplete primary, and 2.99 with no education. The effect of rural residence was small. All coefficients were highly statistically significant. (Table 5)

Table 5: Net effect of race, education and urban residence on risk of terminal celibacy after controlling for time trend and sex, South Africa, cohorts 1961-1971 (age 40-49 in 2011)

\begin{tabular}{llccc}
\hline Variable & Value & Frequency & Relative risk & Significant \\
\hline \multirow{2}{*}{ Race } & Black/African & & & \\
& Coloured & 0.744 & 3.21 & $*$ \\
\multirow{4}{*}{ Education } & Indian/Asian & 0.108 & 1.72 & $*$ \\
& White/European & 0.033 & 0.67 & $*$ \\
& None & 0.115 & 1.00 & Ref \\
& Some primary & 0.078 & 2.99 & $*$ \\
& Primary, complete & 0.154 & 2.57 & $*$ \\
& Some secondary & 0.061 & 2.25 & $*$ \\
& Secondary complete & 0.321 & 1.96 & $*$ \\
Area of & Other level & 0.230 & 1.47 & $*$ \\
residence & Higher education & 0.003 & 1.33 & $*$ \\
\hline
\end{tabular}

NB: Frequency $=$ proportion in the population. 
Running the same regression model by population group, while using more socioeconomic variables, further revealed the complexity of the structures of the South African population. For all population groups, prevalence of terminal celibacy was still increasing with cohort within the 1961-1971 range, more rapidly for Black/African $(+8.1 \%$ a year), and Coloured $(+6.8 \%$ a year), than for Indian/Asian $(+4.4 \%$ a year) and White/European (+3.5\% a year). Differences between men and women were small for Black/African $(R R=1.09)$, and Coloured $(R R=1.07)$, but large for Indian/Asian (RR= 1.28) and White/European $(R R=1.27)$. The effect of education was always large and negative, especially for White/European, but less so for Indian and Coloured. Living in rural areas was associated with lower risk for Black/African, but with higher risks for the three other groups. Being born abroad was associated with a lower risk for all four groups. Patterns of terminal celibacy by province of residence were also compared with Black/African living in the Western Cape, only those living in the Free State had lower risks. Coloured living in the Western Cape had also lower risks. Compared with Indian/Asian living in the Western Cape, those living in Kwazulu-Natal (the majority), Gauteng, and North-West had lower risks. The pattern was different for White/European, who had higher risks in Western Cape and Gauteng, and lower risk elsewhere. Having moved in the past 10 years (since 2001) had a positive effect for Indian/Asian, a negative effect for White/European, and a negligible effect for the other two groups. Being currently employed (in 2011) had always a negative effect, similar for all four groups, reducing the risk of terminal celibacy by about one third. (Table 6)

Table 6: Net effect of socioeconomic and cultural factors (relative risks), South Africa, cohorts 1961-1971

\begin{tabular}{|c|c|c|c|c|c|}
\hline \multirow[b]{2}{*}{ Variable } & \multirow[b]{2}{*}{ Value } & \multicolumn{4}{|c|}{ Population group } \\
\hline & & $\begin{array}{c}\text { Black/ } \\
\text { African }\end{array}$ & Coloured & $\begin{array}{l}\text { Indian/ } \\
\text { Asian }\end{array}$ & $\begin{array}{c}\text { White/ } \\
\text { European }\end{array}$ \\
\hline Percent celibate & Average & $44.6 \%$ & $30.5 \%$ & $12.5 \%$ & $15.7 \%$ \\
\hline Cohort & One year & 1.081 & 1.068 & 1.044 & 1.035 \\
\hline Sex & Sex (male) & 1.092 & 1.074 & 1.278 & 1.270 \\
\hline \multirow[t]{7}{*}{ Education } & None & 2.591 & 2.952 & 1.693 & 3.640 \\
\hline & Some primary & 2.334 & 2.043 & 1.766 & 2.480 \\
\hline & Primary, complete & 2.090 & 1.708 & 1.910 & 2.500 \\
\hline & Some secondary & 1.953 & 1.190 & $(0.922)$ & 1.423 \\
\hline & Secondary complete & 1.535 & 0.892 & $(0.940)$ & 1.199 \\
\hline & Higher education & 1.000 & 1.000 & 1.000 & 1.000 \\
\hline & Other level & 1.304 & 1.654 & $(1.495)$ & $(1.151)$ \\
\hline \multirow[t]{2}{*}{ Area of residence } & Urban & 1.000 & 1.000 & 1.000 & 1.000 \\
\hline & Rural & 0.788 & 1.340 & 2.700 & 1.991 \\
\hline \multirow[t]{4}{*}{ Place of birth } & South Africa & 1.000 & 1.000 & 1.000 & 1.000 \\
\hline & SADC country & 0.772 & $(0.840)$ & 0.282 & $(0.987)$ \\
\hline & Other African & 0.524 & (0.932) & $(1.800)$ & (1.000) \\
\hline & Elsewhere & 0.721 & (0.649) & 0.649 & 0.886 \\
\hline \multirow[t]{9}{*}{ Province } & Western Cape & 1.000 & 1.000 & 1.000 & 1.000 \\
\hline & Eastern Cape & $(1.033)$ & 1.199 & $(1.087)$ & 0.858 \\
\hline & Northern Cape & 1.390 & 1.333 & $(1.105)$ & 0.684 \\
\hline & Free State & 0.857 & 1.274 & (1.082) & 0.768 \\
\hline & Kwazulu Natal & 1.666 & 1.519 & 0.692 & 0.844 \\
\hline & North West & 1.379 & 1.438 & 0.606 & 0.841 \\
\hline & Gauteng & 1.261 & 1.175 & 0.685 & $(1.001)$ \\
\hline & Mpumalanga & 1.558 & (1.169) & $(1.101)$ & 0.729 \\
\hline & Limpopo & 1.063 & (0.916) & 0.590 & 0.639 \\
\hline Migration & Moved since 2001 & 1.024 & (0.958) & 1.194 & 0.741 \\
\hline Employment & Currently employed & 0.698 & 0.643 & 0.681 & 0.685 \\
\hline \multirow[t]{3}{*}{ Language spoken } & English & 1.000 & 1.000 & 1.000 & 1.000 \\
\hline & Afrikaans & 0.852 & 1.665 & 1.496 & 0.689 \\
\hline & Other language & 1.201 & 2.032 & 2.034 & 1.161 \\
\hline
\end{tabular}

NB: Values in parenthesis were not statistically different from 1 ( $P>0.05)$ 
Trends in the marriage market

The marriage market is difficult to analyse in situations where polygamy is culturally acceptable. In general, a balanced number of males and females eligible to marriage is considered conducive to marriage, and any imbalance could potentially lead to involuntary terminal celibacy for one gender but not for the other. In case of polygamy, an excess of women can be easily absorbed, so that a deficit of women could be the reason for an excess of terminal celibacy for men. The eight censuses provided data on the marriage market only for the 1970-2011 period, but not for the first part of the $20^{\text {th }}$ century. Over this later period, that of the large rise in terminal celibacy for both genders, the ratio of unmarried men to unmarried women aged 20-39, called here the 'marriage market ratio' averaged 1.08, which is close to balance with a small excess of males, a situation conducive to universal marriage of women. It was higher than 1 in 1970 (1.30) and in 1980 (1.25), declined over the years to reach a minimum of 0.94 in 2007 then increased again to reach 1.05 in 2011. Trends were roughly similar for all population groups, but at different levels. Therefore, trends in the marriage market were rather conducive to female marriage during the period of fast rise in terminal celibacy, and there were no obvious correlation between both variables (marriage market ratio and terminal celibacy). Only for the White/European group, the marriage market ratio underwent a serious decline, from 1.65 in 1970 to 1.13 in 2011, and could have led to more difficult marriage for women, and easier marriage for men, but in fact the opposite occurred. The fact that the marriage market ratio was low for all groups in 2007 did not seem to have a differential effect on male celibacy. Black/African and Coloured had rather stable and balanced ratios, but still underwent the largest increases in terminal celibacy. (Figure 3)

\section{Figure 3: Marriage market ratio for census years, South Africa}

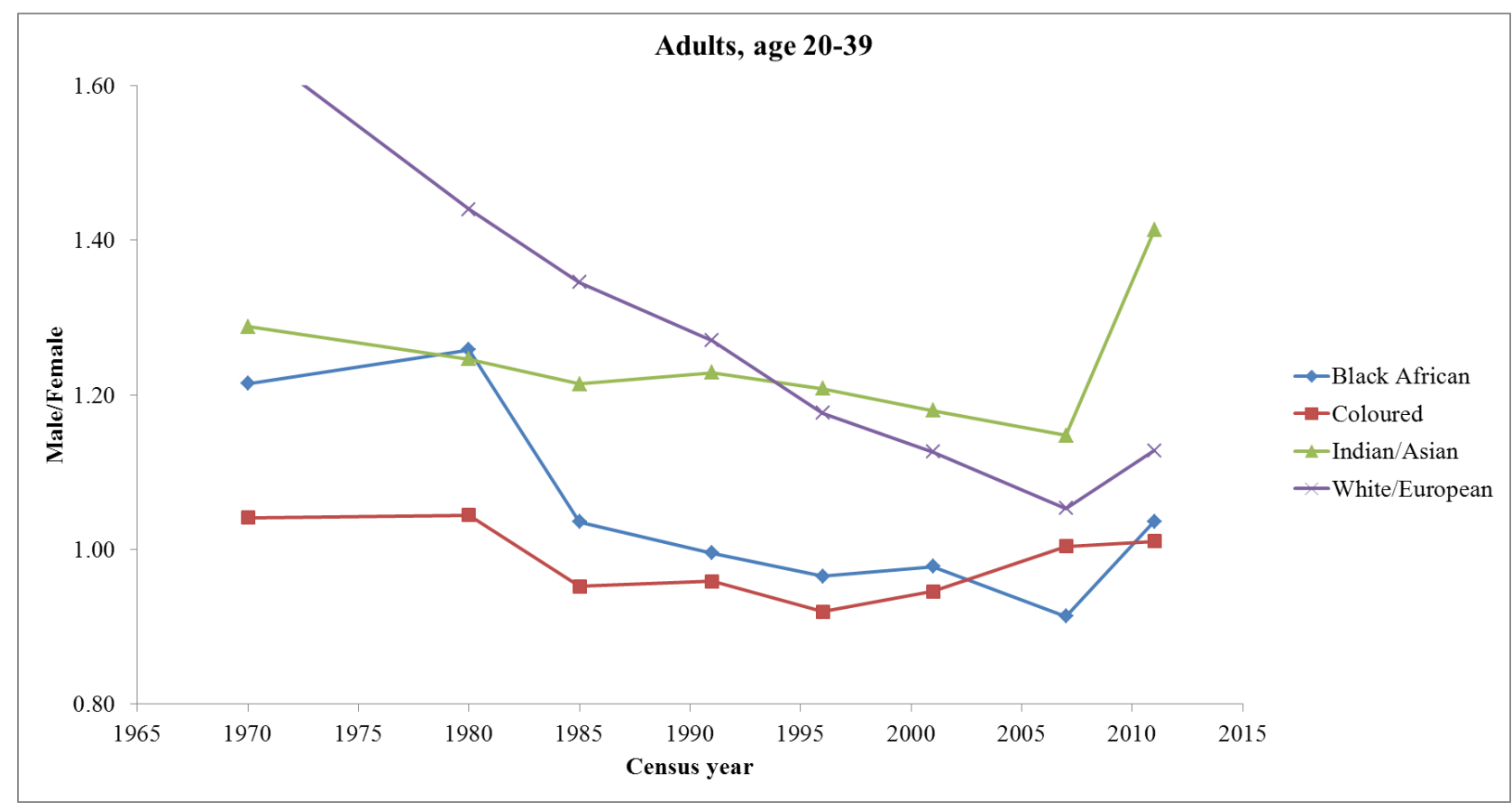

NB: The 'Marriage market ratio' is the ratio of unmarried men age 20-39 to unmarried women of the same age. 


\section{Discussion}

This study of long terms trends in terminal celibacy was made possible by the archiving and the release of census micro-data, thanks to the generous open policy of the statistical office of South Africa (Stat-SA) and to the archiving efforts of IPUMS-International. The censuses covered a 40 year period, and through the mechanics of cohorts available data covered a whole century of nuptiality change. They allowed reconstructing the past history with a reasonable degree of confidence, and provided a new insight in the major social changes that occurred in South Africa in the $20^{\text {th }}$ century.

The impressive levels of terminal celibacy in recent years among Black/Africans are unique in sub-Saharan Africa, if one includes neighbouring country sharing the same history of colonization, mining and industrialization (Namibia, Botswana), and are probably also unique in the world as a whole. The closest group is probably the African/American group in the USA, where the proportions never-married averaged $26 \%$ for cohorts born in 1965-1969 (aged 45-49 in 2014), $24 \%$ for men and $27 \%$ for women, still way below the South African record. [US Census Bureau, 2015] The outstanding levels found in South Africa, with some $50 \%$ of never married men and women, reveal profound changes in the South African society over the past 60 years. An interval of two generations represents a relatively short time interval in human history, a period during which memory is still vivid. The recent generations who do not longer marry had grand-parents who were almost all married some 60 years before. This is a major change for the making of the family, for the organization of the society as a whole, for the status of women, for the social conditions in which children are raised, and many other social characteristics.

Other major changes occurred in South Africa in the second part of the $20^{\text {th }}$ century which probably played a role in the nuptiality changes. This period was marked by the development of the mining industry and the labour system associated to it which had serious consequences on family separation, by rapid industrialization in other sectors as well, by the apartheid regime (1948-1991) and its very repressive laws, and by civil strife which led to its dismantlement. All these factors had numerous effects on the African family, and could, at least in part, explain the disaffection for formal marriage.
The White/European groups, and to a lesser extent the Indian/Asian groups, seem to follow different dynamics, resembling more to what happened in Europe, the United States of America, and other industrialized countries, although with some local features. For instance, in the USA, the proportions never-married were also increasing, but reached lower levels among Hispanic (15\%), White (12\%) and Asian (8\%) groups for the 1965-1969 cohorts. [US Census Bureau 1985] The situation of South African groups remains outstanding for all population groups, revealing specific social dynamics.

Prevalence of terminal celibacy was moderate for those born before 1920, although still way above terminal celibacy in other subSaharan African countries, where marriage was nearly universal for both men and women. For women born before 1900, terminal celibacy was about $10 \%$ for Black/African, Coloured, and White/European, and about 7\% for Indian/Asian. This corresponds to patterns similar to those of Europeans living at the same time in Europe. This could be associated with the market economy system, which had been in place for a long time in South Africa, and implies a different social organization than that of traditional African societies.

An in-depth analysis of the marriage market (equilibrium between men and women) is beyond the scope of this paper. This study showed an overall consistency in levels and trends between men and women. However, there were sometimes different dynamics which might be related with the marriage market. For instance, for those born before 1900, terminal celibacy was more frequent for men than for women for Black/African and for Coloured, but less frequent for Indian/Asian and White/European. These dynamics could be due to a variety of factors, in particular polygyny (polygamy), sex-selective migration, and changing age differences between partners. Polygamy existed traditionally among some of the African groups, and changed over the years. During the $20^{\text {th }}$ century, a majority of in-migrants were males, in particular those working in the mining industry. Lastly, age at marriage also changed, with an effect on the marriage market. All these dynamics deserve further investigation.

Nuptiality trends are determined either by cultural factors (social change, acculturation, group dynamics etc.) or by socio-economic factors (economic development, education, urbanization, etc.), or by the marriage market, or 
by a combination of those elements. In the case of South Africa, multivariate analysis underlined the important role of cultural factors, in particular race and ethnicity, well beyond any socioeconomic factor. Among the demographic phenomenon (mortality, fertility, migration, etc.), nuptiality is the most sensitive to cultural factors, and South Africa is one of the most striking cases of such differences, because of its complex social fabric and its rapid dynamics. Some of the differences could be understood by the different backgrounds of the population groups, while some others by the degree of acculturation or integration of selected ethnic groups. In particular groups who have been in closer contacts with Europeans (Zulu, Swazi, Xhosa) in the $19^{\text {th }}$ and early $20^{\text {th }}$ century seem to have been more affected than more remote groups (Venda, Shangaan). Even among the White/European groups, differences were found between the Afrikaners, who often live more remote and in rural areas, the urban elites speaking English, and the more recent migrants from Europe still speaking their mother tongue at home. Differences in terminal celibacy seem to reveal differences in integration into the modern world and into the local society. These dynamics deserve further investigation in an historical and social perspective.

Socio-economic factors had an unexpected relationship with terminal celibacy, in particular more education, and formal employment were associated with less terminal celibacy. This could be due to the effect of economic stability, because greater opportunities for finding jobs and a regular income are conditions for stable relationships and marriage. This reveals that the make-up of the South African society is different from that of other industrialized countries, where the pattern tends to be opposite, even though relationships between employment and celibacy appear complex. [Sampson 1995; Testa \& Krogh 1995]

Geographic factors require in-depth investigations in South Africa, because of the complex structure of the society. Provinces have different population compositions in terms of race and ethnicity, and different levels of development in terms of income, urbanization, and employment. The multivariate analysis suggests that some differences remained unexplained by cultural and socio-economic factors that were available for this study. In particular, Kwazulu-Natal and Mpumalanga seem to have distinctive features for the Black/African populations.

The effect of the age structure (marriage squeeze) seemed to have been small in the case of South Africa. This was best shown by the fact that both genders appeared to behave the same way. Had there been a strong imbalance between genders, one gender would have continued to marry while the other would not.

The study did not address the implications of highly prevalent terminal celibacy on fertility, population growth and the demographic dividend. In South Africa, fertility trends have been largely independent from nuptiality, and responded primarily to the excellent family planning program put in place in 1974, to economic development, to high level of education and to modernization [Moultrie \& Timaeus 2003, Swartz 2003]. In particular, South Africa is characterized by high prevalence of premarital fertility, that is birth before any marriage, especially among Black/African and Coloured groups. [Garenne et al. 2000; Garenne \& Zwang 2006; Preston-Whyte 1978, 1993] However, it cannot be excluded that the decline in marriage had also contributed to fertility decline. This point deserves further investigation.

The study has some limitations, since terminal celibacy was not based on a rigorous definition of being never-married by age 40 . However, there was no evidence of any serious problem, since no bias was identified according to age or to the recall period. Nevertheless, one shall remember that some persons who were classified in the celibate category could have been married at one point and living with someone at time of the census, while others might have not declared a previous marriage that failed. Errors in declaration are inevitable in a large operation such as a census. Full marriage histories would be needed in order to better understand the potential biases in the census.

\section{Conclusions and future research}

The outstanding situation of nuptiality in South Africa is the result of complex economic and social dynamics, specific to this country and its peculiar history over the past centuries. These profound changes already have many social implications and are likely to have even more in the future.

The future of terminal celibacy appears uncertain in South Africa: will marriage disappear in the next two generations if trends continue at this pace? Will there be a major reversal in trends in the near future? Will new economic opportunities and a more stable social situation be conducive to more marriage? Will there be new incentives for stable marriage? All 
these questions remain open and deserve to be monitored in the future.

\section{Acknowledgements}

The study benefited from the support of the IPUMS-International program.

\section{References}

Budlender D, Chobokoane N, Simelane S. (2004). Marriage patterns in South Africa: methodological and substantive issues. Southern African Journal of Demography 19(1):1-26.

Coale AJ. (1969). The decline of fertility in Europe from the French Revolution to World War II. In: Behrman, S.J., Corsa, L., Jr., and Freedman, R., eds. Fertility and family planning. Ann Arbor, University of Michigan Press, 1969. p. 3-24.

Coale AJ, Cotts-Watkins S. (eds). (1986). The Decline of Fertility in Europe. Princeton, NJ: Princeton University Press.

Dixon RB. (1971). Explaining cross-cultural variations in age of marriage and proportions never marrying. Population Studies; 25: 215233.

Eekelaar JM, Katz SN. (1985). Marriage trends in America: estimates, implications and underlying causes. Population and Development Review; 11: 193-245.

Elliot DB, Krivickas K, Brault MW, Kreider RM. (2012). Historical Marriage Trends from 18902010: A Focus on Race Differences. SEHSD Working Paper Number 2012-12.

Garenne M, Tollman S, Kathleen K. (2000). Marital and premarital fertility in a rural area of South Africa: a challenge to existing population policy. Studies in Family Planning 31(1):47-54.

Garenne M. (2004). Age at marriage and modernization in sub-Saharan Africa. Southern African Journal of Demography; 9(2): 57-77.

Garenne M, Zwang J. (2006). Premarital fertility and ethnicity in Africa. DHS Comparative Reports No. 13. Calverton, Maryland, USA: Macro International Inc. 87 p.

Garenne M. (2014). Trends in Marriage and Contraception in sub-Saharan Africa: A longitudinal perspective on factors of fertility decline. DHS Analytical Studies No 42. Rockville, Maryland, USA: ICF International.

Hosegood V, McGrath N, Moultrie T. (2009). Dispensing with marriage: Marital and partnership trends in rural KwaZulu-Natal, South Africa 2000-2006. Demographic Research; 20: 279-312.
Leonard A, Masebe LO, Medupi M, Matlwa TB. (2015). Marriage patterns in South Africa: analysis of census 1996-2011 data. Paper presented at 7th UAPS conference, Johannesburg, December 2015.

Lesthaeghe RJ, Kaufmann G, Meekers D. (1989). The nuptiality regimes in sub-Saharan Africa. In:. Lesthaeghe RJ. Ed., Reproduction and social organization in sub-Saharan Africa. Berkeley, University of California Press: 238-337.

Mare RD, Winship C. (1991). Socioeconomic change and the decline of marriage for blacks and whites. In: C. Jenks and P. Peterson eds. The urban underclass. Washington DC, The Brookings Institution: 175-202.

Moultrie T, Timaeus I. (2003). The South African fertility decline: evidence from two censuses and a demographic and health survey. Population Studies; 57(3):265-284

Odimegwu C, Kekovole J. (eds.) (2014). Continuity and change in sub-Saharan African demography. Routledge, New York.

Palamuleni. ME. (2010). Recent marriage patterns in South Africa 1996-2007. Bangladesh e-Journal of Sociology; 7(1): 4770.

Preston-Whyte EM. (1978). Families without marriage. In: Social systems and tradition in Southern Africa. Edited by WJ Argyle and EM Preston-Whyte. Cape Town: Oxford University Press.

Preston-Whyte E. (1993). Women who are not married: fertility, 'illegitimacy', and the nature of households and domestic groups among single African women in Durban. South African Journal of Sociology; 24(3): 63-71.

Rodgers WL, Thornton A. (1985). Changing patterns of first marriage in the United States. Demography; 22(2): 265-279.

Rutaremwa G. (2014). Nuptiality patterns and differentials in sub-Saharan Africa: analysis of African Census Data. In: Odimegwu C, Kekovole J. (eds.) (2014). Continuity and change in sub-Saharan African demography. Routledge, New York, pp: 113-129

Sampson RJ. (1995). Unemployment and imbalanced sex ratios. Race-specific consequences for family structure and crime. In: The decline in marriage among AfricanAmericans: causes, consequences, and policy implications. Russel Sage Foundation, New York, USA: 229-254

Stolnitz GJ. (1955). A century of international mortality trends: I. Population Studies (London); 9(1):24-55. 
Stolnitz GJ. (1956). A century of international mortality trends: II. Population Studies (London); 10(1):17-42.

Swartz L. (2003). Fertility transition in South Africa and its implications on the four major population groups. In: Fertility: current South African Issues of Poverty, HIV/AIDS and youth. Human Sciences Research Council. Cape Town, South Africa, HSRC Publishers: 7-26.

Testa M, Krogh M. (1995). The effect of unemployment on marriage among black males in inner-Chicago city. In: The decline in marriage among African-Americans: causes, consequences, and policy implications. Russel Sage Foundation, New York, USA: 59-95.

Thornton A, Freedman D. (1982). Changing attitude toward marriage and single life. Family Planning Perspectives; 14: 297-303.

Tucker MB, Mitchell-Kernan C. (eds). (1995a). The decline in marriage among AfricanAmericans: causes, consequences, and policy implications. Russel Sage Foundation, New York, USA.

Tucker MB, Mitchell-Kernan C. (eds). (1995b). Trends in African-American family formation: a theoretical and statistical overview. In: The decline in marriage among AfricanAmericans: causes, consequences, and policy implications. Russel Sage Foundation, New York, USA: 3-26.
Udjo EO. (2001). Marital patterns and fertility in South Africa: the evidence from the 1996 population census. Paper presented at the XXIV IUSSP general conference, Salvador de Bahia, Brazil.

US Census Bureau. (2015). America's families and living arrangements: 2014: Adults (A table series). Web site: https://www.census.gov/hhes/families/data/cp s2014.html. Accessed July 13, 2015.

van de Walle E. (1967). Marriage in African censuses and inquiries. In: The Demography of Tropical Africa, edited by W. Brass, AJ Coale et al. Princeton, NJ, Princeton University Press: 183-238.

van de Walle E. (1993). Recent trends in marriage ages. In: Demographic change in sub-Saharan Africa; edited by KA Foote, KH Hill, and LG Martin. Washington, DC, National Academy Press: 117-152.

Westoff CF, Blanc A, Nyblade L. (1994). Marriage and entry into parenthood. Demographic and Health Surveys, Comparative Study No 10, $41 \mathrm{p}$.

Westoff CF. (2003). Trends in Marriage and Early Childbearing in Developing Countries. DHS Comparative Reports No. 5. Calverton, Maryland: ORC Macro.

Ziehl SC. (2001). Documenting changing family patterns in South Africa: are census data of any value? African Sociological Review; 5(2): 36-62. 
African Population Studies Vol 30, No 2, (Supp.), 2016

Table A-1: Prevalence of terminal celibacy by cohort \& census, South Africa, all groups combined (percent)

\begin{tabular}{|c|c|c|c|c|c|c|c|c|c|c|}
\hline \multirow[b]{2}{*}{ Census } & \multicolumn{10}{|c|}{ Cohort (year of birth) } \\
\hline & $\begin{array}{l}1880- \\
1889\end{array}$ & $\begin{array}{l}1890- \\
1899\end{array}$ & $\begin{array}{l}1900- \\
1909\end{array}$ & $\begin{array}{l}1910- \\
1919\end{array}$ & $\begin{array}{l}1920- \\
1929\end{array}$ & $\begin{array}{l}1930- \\
1939\end{array}$ & $\begin{array}{l}1940- \\
1949\end{array}$ & $\begin{array}{l}1950- \\
1959\end{array}$ & $\begin{array}{l}1960- \\
1969\end{array}$ & $\begin{array}{l}1970- \\
1971\end{array}$ \\
\hline \multicolumn{11}{|l|}{ Women } \\
\hline 1970 & 4.9 & 5.4 & 6.0 & 7.4 & 10.7 & 13.9 & & & & \\
\hline 1980 & 8.6 & 8.7 & 8.9 & 8.8 & 10.4 & 14.9 & 21.5 & & & \\
\hline 1985 & & & 8.6 & 8.1 & 7.7 & 9.2 & 13.1 & 19.1 & & \\
\hline 1991 & & 8.6 & 9.2 & 8.1 & 9.3 & 12.5 & 17.9 & 23.6 & & \\
\hline 1996 & & & 12.8 & 9.0 & 9.5 & 12.6 & 18.3 & 25.4 & & \\
\hline 2001 & & & & 9.0 & 9.4 & 12.6 & 18.8 & 27.0 & 33.5 & \\
\hline 2007 & & & & 9.3 & 9.7 & 12.4 & 18.4 & 26.2 & 35.9 & \\
\hline 2011 & & & & & 14.6 & 15.9 & 20.1 & 27.3 & 36.4 & 43.8 \\
\hline \multicolumn{11}{|l|}{ Men } \\
\hline 1970 & 6.6 & 7.2 & 8.8 & 10.4 & 13.7 & 18.6 & & & & \\
\hline 1980 & 12.1 & 11.1 & 11.0 & 11.5 & 13.1 & 16.7 & 23.4 & & & \\
\hline 1985 & & & 12.6 & 9.8 & 10.2 & 11.7 & 14.0 & 18.3 & & \\
\hline 1991 & & 11.1 & 9.7 & 9.6 & 11.1 & 13.8 & 17.9 & 24.0 & & \\
\hline 1996 & & & 16.2 & 10.1 & 10.2 & 13.2 & 18.2 & 25.2 & & \\
\hline 2001 & & & & 9.9 & 9.9 & 12.2 & 17.8 & 26.3 & 35.3 & \\
\hline 2007 & & & & 14.9 & 9.6 & 10.5 & 15.9 & 24.0 & 36.1 & \\
\hline 2011 & & & & & 14.0 & 13.0 & 16.7 & 24.2 & 35.9 & 45.9 \\
\hline
\end{tabular}

